\title{
Long-Term Water Temperature Variations in Daya Bay, China Using Satellite and In Situ Observations
}

\author{
Jing $\mathrm{Yu}^{1,2,3, *}$, Danling Tang ${ }^{3}$, Lijun Yao ${ }^{4}$, Pimao Chen ${ }^{1,2}$, Xiaoping Jia ${ }^{1,2}$, and Chunhou $\mathrm{Li}^{1,2}$ \\ ${ }^{1}$ South China Sea Fisheries Research Institute, Chinese Academy of Fishery Sciences, Guangzhou, China \\ ${ }^{2}$ Key Laboratory of Mariculture, Ecology and Quality Control and Key Field Scientific Experimental Station of South Sea Fishery \\ Resource and Environment, Ministry of Agriculture, Guangzhou, China \\ ${ }^{3}$ Research Center of Remote Sensing and Marine Ecology/Environment, Key Laboratory of Tropical Marine Environmental Dynamics, \\ South China Sea Institute of Oceanology, Chinese Academy of Sciences, Guangzhou, China \\ ${ }^{4}$ Department of Electro-Optical Engineering, Jinan University, Guangzhou, China
}

Received 18 February 2009, accepted 26 May 2009

\begin{abstract}
Daya Bay is a shallow, semi-enclosed bay in the northern section of the South China Sea. The present study analyzed variations of water temperature in Daya Bay over the past 21 years (1985 - 2005) using Advanced Very High Resolution Radiometer (AVHRR) satellite remote sensing data and in situ observations. Results showed that AVHRR readings of sea surface temperature (SST) increased by $0.07^{\circ} \mathrm{C}^{-1}$. Linear regression analysis for monthly SST anomalies (SSTA) showed a shift from negative to positive from 1995 - 1996, when the Daya Bay nuclear power station commenced operations in 1994. The slope of linear regression analysis for SSTA nearly doubled from 0.05 (1985 - 1993) to 0.09 (1994 - 2005). Monthly AVHRR images showed a thermal plume from the power station and revealed the increase of SST over 21 years. In situ observations in water temperature also showed an increasing trend for the same period (1985 - 2005). Variations in water temperature in Daya Bay were connected with climatic perturbations and increasing human activity including thermal discharge from nuclear power stations and the rapid economic development around the bay area.
\end{abstract}

Key words: Sea surface temperature, AVHRR, Remote sensing, In situ observation, Daya Bay, China

Citation: Yu, J., D. Tang, L. Yao, P. Chen, X. Jia, and C. Li., 2010: Long-term water temperature variations in Daya Bay, China using satellite and in situ observations. Terr. Atmos. Ocean. Sci., 21, 393-399, doi: 10.3319/TAO.2009.05.26.01(Oc)

\section{INTRODUCTION}

Daya Bay is located in the northern section of the South China Sea (SCS; Fig. 1a). It was one of the major aquacultural areas in the Guangdong province because of its excellent water quality and rich biological resources (Xu 1989). Since the late 1980 s, economic development in industry, aquaculture, and agriculture in the area has rapidly expanded. For example, the first large-capacity commercial nuclear power unit in China, the Daya Bay nuclear power station (DNPS), commenced operation in early 1994. Near the DNPS, another nuclear power station, the Lingao nuclear power station (LNPS), has also been in operation since 2003 (http://www.cgnpc.com.cn). The two nuclear power stations have been continuously discharging thermal water to Daya Bay since their operation (http://www.cgnpc.com.cn).

\footnotetext{
* Corresponding author

E-mail:yj_scs@163.com
}

Other industries such as those on petrochemicals, printing, harbors, and tourism are also present (Fig. 1b). Due to the activities of these industries, the water quality status of Daya Bay has deteriorated (Zhou and Maskaoui 2003), and the environmental condition in its waters has changed ( $\mathrm{Yu}$ et al. 2007b). As a result, the occurrences of Harmful Algal Bloom (HAB) in the bay area have become more frequent in recent years. The occurrence season of $\mathrm{HAB}$ has become longer, and new warm-water algal species have caused HAB in the Daya Bay (Yu et al. 2007a).

With the development of space technology, more remote sensing data are currently available for monitoring and studying the marine environment. Satellite remote sensing can complement in situ observation for providing additional information on spatial and temporal variations (Tang et al. 2003; Wynne et al. 2005). Compared with the high costs of monitoring using traditional methods, satellite remote sens- 


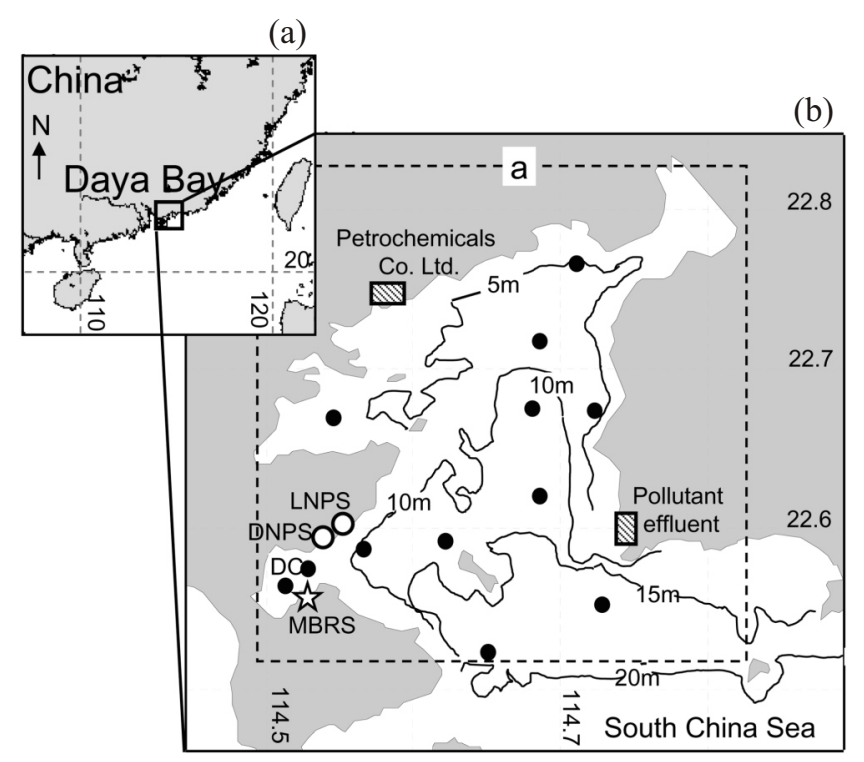

Fig. 1. Research area. (a) Location of Daya Bay. (b) Daya Bay map with depth contour. Circles indicate the location of nuclear power stations (DNPS and LNPS) at the mouth of the Dapeng Cove (DC). Small boxes with shadows show Petrochemicals Co. Ltd. in the northwest of Daya Bay and its pollutant effluents in the east of the bay. Box a indicated by dashed lines shows the sample area where AVHRR SST data were derived from. The twelve survey stations are represented by black dots.

ing provides an economical method. Among various satellite sensors, the Advanced Very High Resolution Radiometer (AVHRR) onboard the National Oceanic and Atmospheric Administration (NOAA) polar orbiting satellites has a longterm record of Sea Surface Temperature (SST) for more than 20 years, and has made investigating the status of the sea surface more convenient. Previous studies have observed the seasonal distribution of SST in Daya Bay through daily AVHRR images (Tang et al. 2003) and Landsat Thematic Mapper (TM) images (Chen et al. 2003). However, little attention has been given on studying the long-term variations of water temperature and ecological response in Daya Bay.

Daya Bay has experienced long-term development that has profoundly changed its ecological and economic landscapes. As such, it provides a unique opportunity to study the response of a particular marine environment to natural variability and anthropologic influence in the bay area. In order to obtain a better understanding of the marine environmental changes in Daya Bay, we have attempted to analyze the temporal and spatial changes in water temperature using longterm satellite remote sensing and in situ data. The results of this work will help better evaluate the response of marine environment to human activities and natural changes in the bay area.

\section{RESEARCH AREA AND DATA}

\subsection{Research Area}

Daya Bay is a shallow semi-enclosed bay located at $22^{\circ} 30^{\prime}-22^{\circ} 50^{\prime} \mathrm{N}, 114^{\circ} 30^{\prime}-114^{\circ} 50^{\prime} \mathrm{E}$, in the northern section of the South China Sea (SCS; Fig. 1). It covers an area of about $600 \mathrm{~km}^{2}$ with an irregular coastline and more than 50 islands inside the bay area. The deepest site is $21 \mathrm{~m}$ near the bay mouth, and the average water depth is $11 \mathrm{~m}$. No major rivers discharge into Daya Bay, and water exchange inside the bay and the SCS is mainly through the bay mouth (Xu 1989). According to long-term observation and measurements, the tidal current in Daya Bay is dominated by an irregular semi-diurnal tide (semi-diurnal tides predominate with diurnal tides occurring during a lunar month) with an average tidal day of about $24.7 \mathrm{~h}$. The average tidal range is $1.01 \mathrm{~m}$, and the maximum is $2.57 \mathrm{~m}$ (Zeng et al. 2002).

\subsection{Satellite Remote Sensing Data}

The AVHRR onboard NOAA's Polar Orbiting Environmental Satellites (POES) is a broad-band, four- or five-channel scanner, sensing in the visible, near-infrared, and thermal infrared portions of the electromagnetic spectrum. (http:// edcsns17.cr.usgs.gov/1KM/avhrr_sensor.html). It has continuously provided SST information since 1978 and at scale that had previously been impossible to achieve through mere ship observation.

In this study, a total of 7614 NOAA-AVHRR SST data with $4 \mathrm{~km}$ spatial resolution from January 1985 to December 2005 were obtained from the NASA Jet Propulsion Laboratory (JPL) Physical Oceanography Distributed Active Archive Center (PO-DAAC) PATHFINDER database (http:// podaac.jpl.nasa.gov/index.html). At the same time, ASCII format data were derived from those AVHRR SST data for the sample area of box a $\left(22.50-22.83^{\circ} \mathrm{N}, 114.50-114.82^{\circ} \mathrm{E}\right.$; indicated by box a in Fig. 1b) through the MATLAB 7.0.1 software package. The obtained ASCII format SST data were then processed to yearly and monthly values. Linear regression analysis performed on yearly and monthly SST showed an increasing rate in SST per year and month. In order to remove the season signal, monthly SST anomaly (SSTA) was calculated from monthly SST minus monthly mean SST averaged for 21 years (1985 - 2005). For a better understanding of the SST distribution, we processed SST data sets with $1 \mathrm{~km}$ spatial resolution from 1985 - 2005 to monthly average images through Grid Analysis and Display System (GRADS). Both 1 and $4 \mathrm{~km}$ spatial resolution SST data were night products.

\subsection{In Situ Data}

The South China Sea Institute of Oceanology (SCSIO) of the Chinese Academy of Sciences has one Marine Biological Research Station (MBRS in Fig. 1b) in Dapeng Cove (DC in Fig. 1b). It has carried out a series of surveys over 12 stations in Daya Bay since 1982 (Black dots in Fig. 1b). Some environmental and biological factors such as seawater 
temperature, $\mathrm{Chl} a$, nutrients, $\mathrm{pH}$, and biomass of the biota have been investigated seasonally every year (http://www. cern.ac.cn:8080/index.jsp). We tried to obtain all the in situ Water Surface Temperature (WST) data; the earliest record of WST in the Daya Bay was in 1970 and there were no data from 1971 - 1981. In situ WST data were obtained from a series of research cruises in Daya Bay (conducted by our research group and MBRS), the Chinese Ecosystem Research Network (CERN), and the "Annual Report of Daya Bay Environment Research." A total of 1845 in situ WST data from January 1970 to November 2005 were processed to annual mean values and then analyzed in this study.

All in situ WST data conducted through a series of research cruises were measured following standard methods (SOC 1991). Based on water depth, water samples were collected in the surface layer at less than $5 \mathrm{~m}$; surface and bottom layer for 5 - $10 \mathrm{~m}$; and surface, middle, and bottom layer for more than $10 \mathrm{~m}$. Sampling depth and water temperature were measured in situ by a YSI 6600 multi-parameter water quality monitor.

\section{RESULTS}

\subsection{Annual Increase of SST}

Annual mean SST from $1985-2005$ varied from $18.35^{\circ} \mathrm{C}$ (1988) to $20.87^{\circ} \mathrm{C}$ (2005; Fig. 2a). Linear regression analysis for SST showed an ascending trend with a slope of 0.07 over the past two decades, indicating that SST increased by $0.07^{\circ} \mathrm{C} \mathrm{y}^{-1}$ (Fig. 2a). The total number of annual SST data ranged from 357 to 366 , covering each month throughout the year (Fig. 2b).

\subsection{Seasonal Variation in SST}

To investigate the changes in SST in Daya Bay over the past two decades, we processed $4 \mathrm{~km}$ spatial resolution SST data to a time series of monthly mean SST from 1985 - 2005 (Fig. 3a). The minimum SST was $11.5^{\circ} \mathrm{C}$ (February 1992), and the maximum SST was $26.4^{\circ} \mathrm{C}$ (July 2005). For most years, there was a single maximum SST with its value higher than $25^{\circ} \mathrm{C}$. Linear regression analysis performed on monthly SST from 1985 - 2005 showed an ascending trend at a rate of $0.007^{\circ} \mathrm{C} \mathrm{m}^{-1}$ (Fig. 3a).

Additionally, SSTA was analyzed for two periods: 1985 - 1993 and 1994 - 2005 (Figs. 3b, c). During the first period (1985 - 1993), SSTA ranged from -2.92 (February 1992) to 2.55 (May 1985; Fig. 3b); while during the second period (1994 - 2005), it experienced a larger range from -4.48 (July 1999 ) to 4.44 (November 2005; Fig. 3c). For the entire observation period (1985 - 2005), the trend identified through the linear regression analysis based on SSTA shifted from negative to positive from 1995 - 1996, when the DNPS commenced operation in 1994 (Figs. 3b, c). As can be seen, the slope of linear regression nearly doubled from 0.05 (1985 -
1993) to 0.09 (1994 - 2005).

\subsection{Thermal Plume Distribution}

The monthly mean SST in winter (January), spring (April), summer (July), and fall (October) in 1985 and 2005 were processed into images to show the SST spatial distribution (Fig. 4). For a better comparison of SST in the same month, the same color bar was used for the same month. Compared with SST in 1985, SST in 2005 was higher by about $5^{\circ} \mathrm{C}$ in January (Fig. 4 a), $6^{\circ} \mathrm{C}$ in April (Fig. $4 \mathrm{~b}$ ), $8^{\circ} \mathrm{C}$ in July (Fig. 4c), and $3^{\circ} \mathrm{C}$ in October (Fig. 4d). For a better display of the thermal plume distribution, color bars with different scales were used in different seasons. In 2005, a thermal plume that was about $2^{\circ} \mathrm{C}$ higher than the ambient waters was distributed in the Dapeng Cove (DC in Fig. 4), where the two nuclear power plants are located. In 1985, SSTs in the DC were equal to or relatively lower than those in other waters in the Daya Bay.

A thermal plume that was about $1-2^{\circ} \mathrm{C}$ higher than the adjacent waters in the bay was observed in the satellite images in 2005 (Fig. 4). It was located near the output of the nuclear power stations in January (Fig. 4a), spread to the northeast of Daya Bay in April (Fig. 4b), extended to the southeast of the bay in July (Fig. 4c), and reached up to the northwest of the bay in October (Fig. 4d).

\subsection{In Situ Water Temperature Observation}

In this study, in situ WST for a longer period from 1970 2005 was investigated (no data in 1971 - 1981). Annual mean WST ranged from $21.6^{\circ} \mathrm{C}(1986)$ to $26.6^{\circ} \mathrm{C}(1999$;
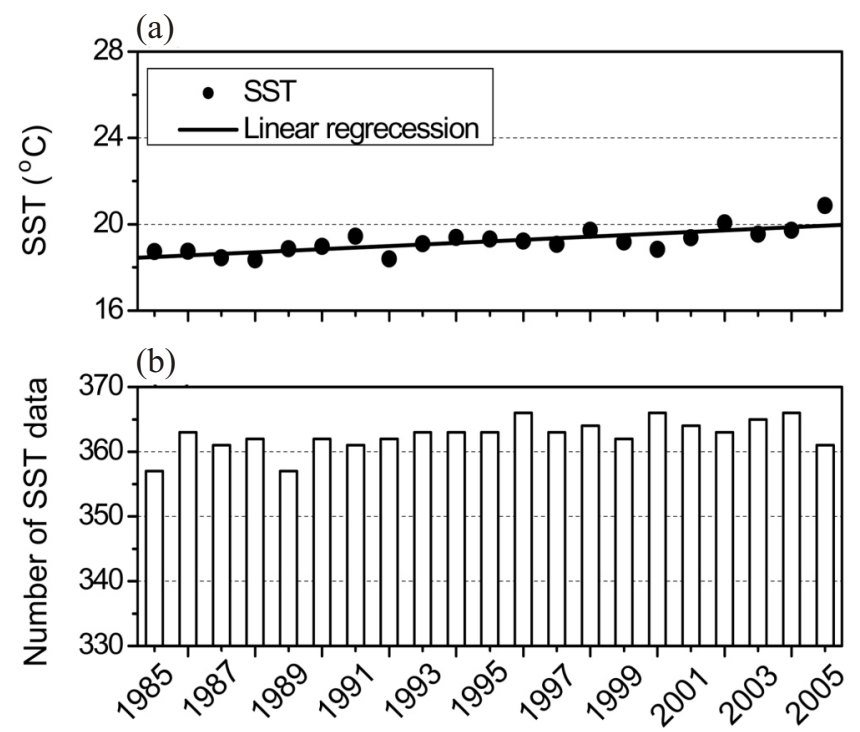

Fig. 2. (a) Time series of annual mean sea surface temperature (SST) derived from NOAA-AVHRR data from 1985 - 2005. (b) Number of SST data for each year. 


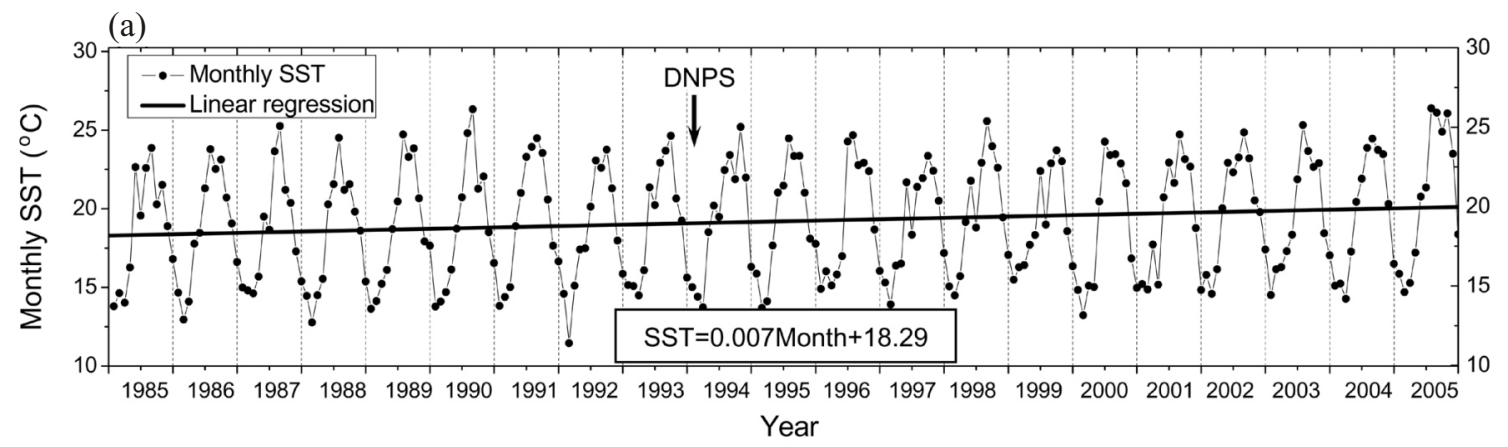

(b)

(c)

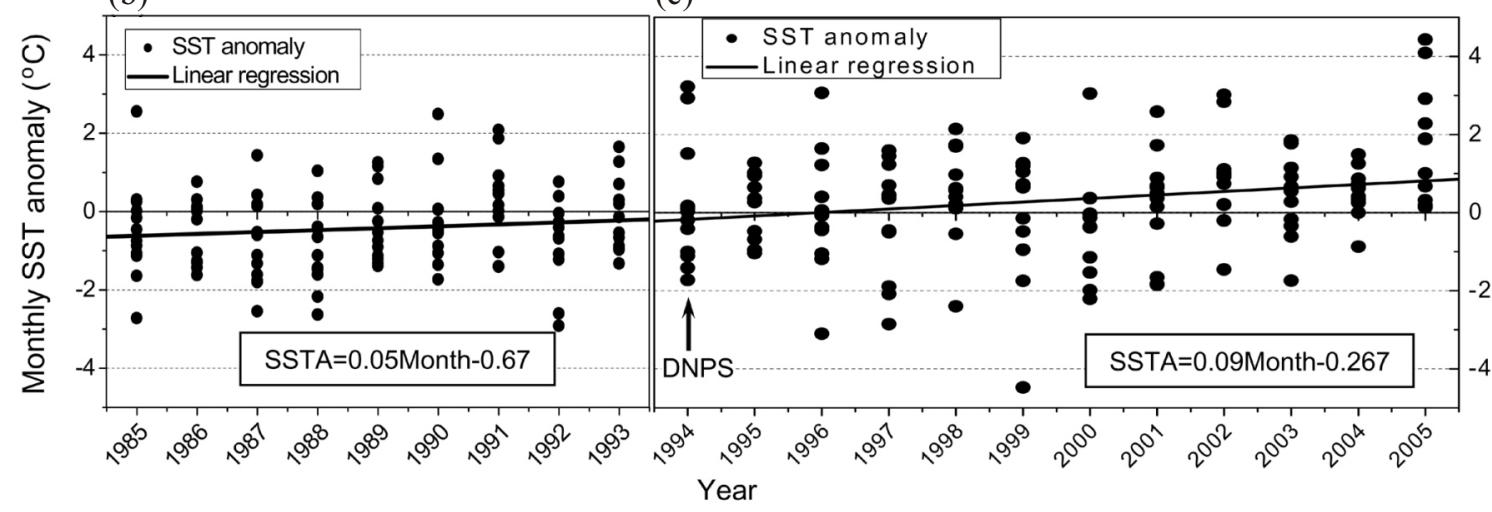

Fig. 3. (a) Time series of monthly mean SST from 1985 - 2005. Black arrows indicate the year when the first nuclear power station (DNPS) commenced operation. (b) Monthly SST anomaly (SSTA) from 1985 - 1993. (c) Monthly SSTA from 1994 - 2005.

(a) January
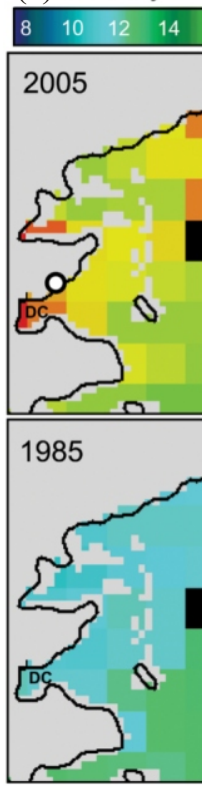

(b) April

(c) July

\begin{tabular}{|lllllll|}
\hline 8 & 12 & 16 & 20 & 24 & 28 & 32 \\
\hline
\end{tabular}

(d) October

\begin{tabular}{lllllll|}
\hline 8 & 12 & 16 & 20 & 24 & 28 & 32 \\
\hline
\end{tabular}

Fig. 4. Comparison of seasonal SST in 1985 and 2005. (a) January, (b) April, (c) July, and (d) October. The circle indicates the location of the nuclear power stations (NPS). DC: Dapeng Cove.

Fig. 5a). Linear regression analysis performed on the annual mean WST from 1985 - 2005 showed an increasing trend and its slope was 0.12 (Fig. 5a). The number of WST data for each year is displayed in Fig. 5b. The WSTs in 1989,
1990, and 1995 were excluded from the linear regression analysis, because the WSTs in those years were sampled in limited months. In 1989, WST was sampled in summer, and in 1990 and 1995, WST was sampled in winter and spring 


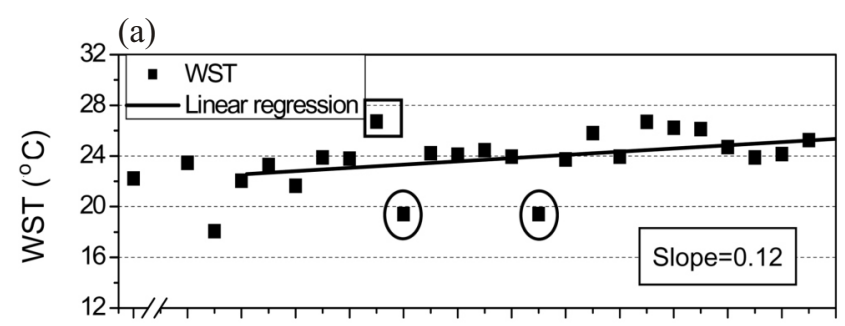

(b)

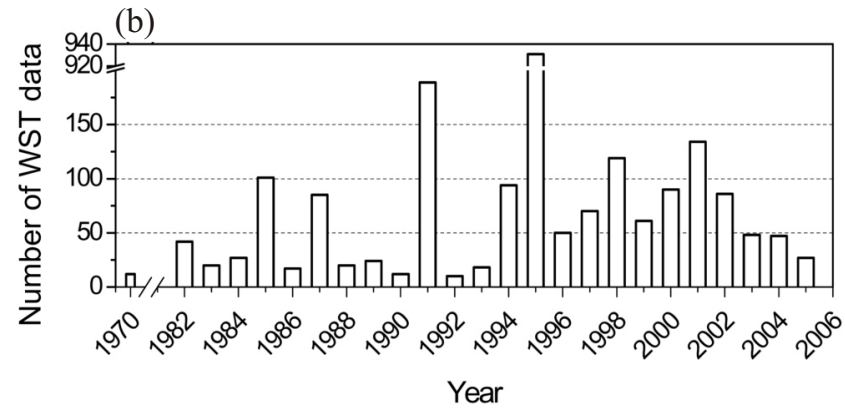

Fig. 5. (a) Annual mean in situ water surface temperature (WST) from 1970 - 2005. The black line indicates linear regression for yearly mean WST (no data was obtained from 1971 - 1981). (b) Number of WST data for each year.

(Fig. 5b). This is one of the reasons why higher or lower WST was displayed in those years.

\section{DISCUSSION}

An increase in water temperature in Daya Bay was observed through both satellite remote sensing and in situ observations, coinciding with the increase of human activities such as thermal discharge from nuclear power stations in the bay area, and global warming.

\subsection{Environmental Change}

From 1985 - 1993, before the NPS operation, SSTA has allowed us to indicate the response of water temperature to natural variability (Fig. 3b). The trend of linear regression during this period was negative (Fig. 3b), indicating that water temperature was relatively low and increased slowly, compared to the entire observation period (1985 - 2005). Since the 1980s, weather temperature in the Daya Bay has been increasing and has been higher than the global temperature by $0.3-0.4^{\circ} \mathrm{C}$ (Yu et al. 2001). In the past 50 years (mid-1950s to mid-1990s), the global mean ocean temperature has increased by $0.31^{\circ} \mathrm{C}$, due to the combination of natural variability and anthropogenic effects (Levitus et al. 2000). At the same time, the respective heat content levels of the world's oceans have increased, and the average rate of sealevel change obtained from tide gauges is $+1.8 \pm 0.3 \mathrm{~mm} \mathrm{yr}^{-1}$, because of the increase of anthropogenic gases in the Earth's atmosphere (Levitus et al. 2001; Nerem et al. 2006). In China, surface water temperature in the Bohai Sea, which is a shallow semi-enclosed sea without a power plant, increased at a rate of $0.011^{\circ} \mathrm{C}^{-1}$ from 1960 - 1997 (Lin et al. 2001). The present study likewise observed an increasing trend in SST in Daya Bay from 1985 - 1993, which is a period prior to the DNPS operation. This indicates Daya Bay's response to the global warming (Fig. 3b).

Apart from the influence of natural variability, anthropogenic effects are also considered important. Daya Bay has experienced remarkable changes over the past two decades, especially after 1994. Aquacultural, industrial and agricultural activities, as well as developments in tourism and the construction of harbors and highways, have rapidly expanded in the area. Aquaculture increased dramatically from 1000 pens in 1988 to 20500 pens in 2004, while permanent resident population around Daya Bay doubled from 1.2 million in 1979 to 2.4 million in 1997 with additional 1 - 1.2 million nonresidents in the area (http://www.huizhou. gov.cn/). The rapid urbanization around Daya Bay has contributed to the elevation of water temperature in this area (Chen et al. 2006).

\subsection{Thermal Discharge from Nuclear Power Station (NPS)}

The DNPS and LNPS discharge thermal water $8-10^{\circ} \mathrm{C}$ higher than the adjacent waters to Daya Bay through one pipe at a rate of $190 \mathrm{~m}^{3} \mathrm{~s}^{-1}$ (Tang et al. 2003; Yu et al. 2007a, b). This thermal plume spreads several square kilometers away from the NPS (Fig. 4). A comparison of in situ WST data near the DNPS showed that the WST increased by $0.77^{\circ} \mathrm{C}$ from 1993 - 1998 (Peng et al. 2001). The present study observed a rapid increase of SST $\left(0.07^{\circ} \mathrm{C} \mathrm{y}^{-1}\right.$ from 1985 - 2005) in Daya Bay, higher than that in Bohai Sea $\left(0.011^{\circ} \mathrm{C}^{-1}\right.$ from $\left.1960-1997\right)$, which is also a semi-enclosed bay but without a power plant (Lin et al. 2001). This may reveal the influence of thermal discharge from the power stations on the marine environment.

Monthly SST and SSTA from 1985 - 2005 also showed an increasing trend in water temperature in Daya Bay (Fig. 3). From 1994 - 2005, after the NPS operation, SSTA has helped indicate the influence of thermal discharge from the NPS to water temperature in Daya Bay (Fig. 3c). The trend of linear regression shifted from negative to positive $1-2$ years after the DNPS operation, indicating the extension of thermal plume from the NPS to the entire bay area. In addition, the slope comparison between the two periods (1985 - 1993 and 1994 - 2005) also showed a more rapid increase of water temperature after the NPS began its operation (Figs. 3b, c). A previous study has observed the seasonal distribution of SST through daily AVHRR satellite images (Tang et al. 2003), while the present study compared the monthly AVHRR images in 1985 and 2005 (Fig. 4). Both studies observed high-temperature water near the NPS and its extension in the bay area. For the same month, SST in 2005 was higher than that in 1985, showing the in- 
crease of water temperature in the entire bay.

The increase of in situ WST in Daya Bay from 1970 $2005\left(0.11^{\circ} \mathrm{C} \mathrm{y}^{-1}\right)$ was higher than that of satellite SST $\left(0.07^{\circ} \mathrm{C}^{-1}\right)$, and its variation had a larger range than that of satellite SST (Figs. 2, 5). One of the possible reasons was that the in situ WSTs were acquired only in the daytime while satellite SST was derived from nighttime products. It was also possible that the sampling season, station, and number of in situ observations were limited.

Daya Bay is a semi-enclosed bay; water circulation with the SCS is slow, with a current velocity lower than $0.5 \mathrm{~m} \mathrm{~s}^{-1}$ (Xu 1989). A field investigation showed that the water surface temperature of the thermal plume discharged from the DNPS decreased slowly at $0.001{ }^{\circ} \mathrm{C} \mathrm{m}^{-1}$ within a distance of $2000 \mathrm{~m}$ from the wastewater outlet, and that the thermal plume extended at least 10 kilometers (Zeng et al. 2002). By comparison, in the southernmost coast of Taiwan, water temperature from the outlet of a coastal nuclear power station decreased quickly at $0.01{ }^{\circ} \mathrm{C} \mathrm{m}^{-1}$ within a distance of $500-800 \mathrm{~m}$ from the outlet (Jan et al. 2004). Furthermore, bays, compared to open waters, generally had a more amplified response in SST (Mustard et al. 1999; Fox et al. 2000). Therefore, the increase in water temperature in the bay area is generally higher than that in coastal waters. Relevant studies on water temperature near power plants also showed warming effects, especially in the bay area (Keser et al. 2003; Poornima et al. 2006). The DNPS has been discharging warm water to the bay for more than 10 years, thereby exacerbating water temperature elevation in the bay area.

\subsection{Ecological Response to the Increase in Water Temperature}

Increased water temperature may affect water quality, aquatic organisms and ecosystem, as well as further impact coastal zones and humanity in general. In Daya Bay, water temperature is one of the major factors influencing the local ecology and environment (Wu and Wang 2007). After the operation of DNPS in 1994, the atomic N : P ratios increased, while the atomic $\mathrm{Si}$ : $\mathrm{P}$ ratios decreased more rapidly, indicating that the nutrient structure has substantially changed (Yu et al. 2007a). The phytoplankton community inside the bay has also changed. The amount of warm-water species increased and net-phytoplankton decreased; Chlorophyll a concentration likewise increased, showing the trend of smaller community (Sun et al. 2006; Wang et al. 2006; Yu et al. 2007b). After 1994, the frequency of HAB in Daya Bay increased, the HAB-affected area spread, and the occurrence season became longer (Yu et al. 2007a). Fisheries resources declined and the fisheries became limited to a small community (Wang et al. 2008). The Daya Bay ecosystem is undergoing a rapid deterioration in some aspects, due to the increase in water temperature.

\section{CONCLUSION}

This study investigated SST changes in a bay area through satellite remote sensing and in situ observations over a long period (21 years). Results showed that:

1. Sea surface temperature increased by $0.07^{\circ} \mathrm{C} \mathrm{y}^{-1}$ for the past 21 years $(1985$ - 2005). It increased more rapidly after 1994, when the first NPS commenced operation, coinciding with thermal discharge from the NPS.

2. Both anthropogenic and climatic perturbations influenced water temperature in the Daya Bay.

3. The Daya Bay ecosystem is undergoing a rapid deterioration, notably the increased frequency and occurrence season of HAB. This is connected with the increase in water temperature in the bay area over the past two decades.

Acknowledgements This study was jointly funded by the following: (a) the Guangdong Natural Science Foundation, China (8451030002001714, 8351030101000002); (b) the High-tech Research and Development Program of China (2006AA100303); (c) the South China Sea Fisheries Research Institute, Chinese Academy of Fishery Sciences (2009TS22, 2007-8, 2007ZD03, 2007ZD08); (d) the Scientific Research Institution Public Welfare Specialized Projects of Ministry of Science and Technology, China (2005DIB3J020); and (e) the Chinese Academy of Sciences (kzcx2-yw-226).

\section{REFERENCES}

Chen, C. Q., P. Shi, and Q. Mao, 2003: Application of remote sensing techniques for monitoring the thermal pollution of cooling-water discharge from nuclear power plant. $J$. Environ. Sci. Heal. A, 38, 1659-1668, doi: 10.1081/ESE120021487. [Link]

Chen, X.-L., H.-M. Zhao, P.-X. Li, and Z.-Y. Yin, 2006: Remote sensing image-based analysis of the relationship between urban heat island and land use/cover changes. Remote Sens. Environ., 104, 133-146, doi: 10.1016/j.rse.2005.11. 016. [Link]

Fox, M. F., D. R. Kester, J. E. Andrews, A. Magnuson, and C. G. Zoski, 2000: Seasonal warming of Narragansett Bay and Rhode Island Sound in 1997: Advanced very high resolution radiometer sea surface temperature and in situ measurements. J. Geophys. Res., 105, 22071-22082, doi: 10. 1029/1999JC000146. [Link]

Jan, S., C.-T. A. Chen, Y.-Y. Tu, and H.-S. Tsai, 2004: Physical properties of thermal plumes from a nuclear power plant in the southernmost Taiwan. J. Mar. Sci. Technol., 12, 433441.

Keser, M., J. T. Swenarton, J. M. Vozarik, and J. F. Foertch, 2003: Decline in eelgrass (Zostera marina L.) in Long Island Sound near Millstone Point, Connecticut (USA) unrelated to thermal input. J. Sea Res., 49, 11-26, doi: 10.1016/ 


\section{S1385-1101(02)00196-X. [Link]}

Levitus, S., J. I. Antonov, T. P. Boyer, and C. Stephens, 2000: Warming of the world ocean. Science, 287, 2225-2229, doi: 10.1126/science.287.5461.2225. [Link]

Levitus, S., J. I. Antonov, J. Wang, T. L. Delworth, K. W. Dixon, and A. J. Broccoli, 2001: Anthropogenic warming of earth's climate system. Science, 292, 267-270, doi: 10.1126/science.1058154. [Link]

Lin, C., J. Su, B. Xu, and Q. Tang, 2001: Long-term variations of temperature and salinity of the Bohai Sea and their influence on its ecosystem. Prog. Oceanogr., 49, 7-19, doi: 10.1016/S0079-6611(01)00013-1. [Link]

Mustard, J. F., M. A. Carney, and A. Sen, 1999: The use of satellite data to quantify thermal effluent impacts. Estuar. Coast. Shelf Sci., 49, 509-524, doi: 10.1006/ecss.1999.0517. [Link]

Nerem, R. S., É. Leuliette, and A. Cazenave, 2006: Present-day sea-level change: A review. C. R. Geosci., 338, 1077-1083, doi: 10.1016/j.crte.2006.09.001. [Link]

Peng, Y. H., H. R. Chen, M. X. Pan, H. H. Huang, and H. L. Gao, 2001: The primary production and potential fishery production in the sea area around the Daya Bay Nuclear Power Station before and after the operation of DBNPS. Journal of Fisheries of China. 25, 161-165. (in Chinese)

Poornima, E. H., M. Rajadurai, V. N. R. Rao, S. V. Narasimhan, and V. P. Venugopalan, 2006: Use of coastal waters as condenser coolant in electric power plants: Imapct on phytoplankton and primary productivity. J. Therm. Biol., 31, 556-564, doi: 10.1016/j.jtherbio.2006.05.009. [Link]

Sun, C. C., Y. S. Wang, S. Sun, and F. Q. Zhang, 2006: Dynamic analysis of phytoplankton community characteristics in Daya Bay, China. Acta Ecologica Sinica, 26, 3948-3958, doi: 10.1016/S1872-2032(07)60005-5. [Link]

Tang, D. L., D. R. Kester, Z. D. Wang, J. S. Lian, and H. Kawamura, 2003: AVHRR satellite remote sensing and shipboard measurements of the thermal plume from the Daya Bay, nuclear power station, China. Remote Sens. Environ., 84, 506-515, doi: 10.1016/S0034-4257(02)001499. $[$ Link $]$

Wang, Z. H., Y. Z. Qi, J. F. Chen, N. Xu, and Y. F. Yang, 2006:
Phytoplankton abundance, community structure and nutrients in cultural area of Daya Bay, South China Sea. J. Mar. Syst., 62, 85-94, doi: 10.1016/j.jmarsys.2006.04.008. [Link]

Wang, Y.-S., Z.-P. Lou, C.-C. Sun, and S. Sun, 2008: Ecological environment changes in Daya Bay, China, from 1982 to 2004. Mar. Pollut. Bull., 56, 1871-1879, doi: 10.1016/j. marpolbul.2008.07.017. [Link]

Wu, M.-L. and Y.-S. Wang, 2007: Using chemometrics to evaluate anthropogenic effects in Daya Bay, China. Estuar. Coast. Shelf Sci., 72, 732-742, doi: 10.1016/j.ecss.2006. 11.032. [Link]

Wynne, T. T., R. P. Stumpf, M. C. Tomlinson, V. Ransibrahmanakul, and T. A. Villareal, 2005: Detecting Karenia brevis blooms and algal resuspension in the western Gulf of Mexico with satellite ocean color imagery. Harmful Algae, 4, 992-1003, doi: 10.1016/j.hal.2005.02.004. [Link]

Xu, G. Z., 1989: Environments and Resources of Daya Bay. Anhui Science Publishing House, Hefei, 6-9. (in Chinese)

Yu, J., D. L. Tang, I. S. Oh, and L. J. Yao, 2007a: Response of harmful algal blooms to environmental changes in Daya Bay, China. Terr. Atmos. Ocean. Sci. 18, 1011-1027, doi: 10.3319/TAO.2007.18.5.1011(Oc). [Link]

Yu, J., D. L. Tang, S. F. Wang, J. S. Lian, and Y. S. Wang, 2007b: Changes of water temperature and harmful algal bloom in Daya Bay in the northern South China Sea. Mar. Sci. Bull., 9, 25-33.

Yu, K. F., Z. D. Wang, and J. S. Lian, 2001: The last fifty years climate fluctuating trends in the Daya Bay as well as its adjacent areas. In: Pan, J. P., Z. D. Wang, and Z. X. Wu (Eds.), Ecological Environment and Sustainability in Marine Biological Resources of Gulf, Science Press, Beijing, 1-9. (in Chinese)

Zeng, P., H. Chen, B. Ao, P. Ji, X. Wang, and Z. Ou, 2002: Transport of waste heat from a nuclear power plant into coastal water. Coast Eng., 44, 301-319, doi: 10.1016/ S0378-3839(01)00039-4. [Link]

Zhou, J. L. and K. Maskaoui, 2003: Distribution of polycyclic aromatic hydrocarbons in water and surface sediments from Daya Bay, China. Environ. Pollut., 121, 269-281, doi: 10.1016/S0269-7491(02)00215-4. [Link] 